\title{
In other words
}

\section{Emergency haiku}

A s an emergency and urgent care psychiatrist, I find that writing haiku engenders a sense of purposeful focus in the midst of emotionally charged clinical work. I began exploring this poetic form with a "haiku kit." This consisted of a book on haiku writing, a drawstring bag containing an assortment of words from which a poem can be created, and a blank book for the writer's own creations. Haiku writing and its evocative repetition of meaningful themes can induce a meditative state and, over time, a sense of wholeness. On two occasions, I chose the word "blossom." Here are the results:

through gentle snow crust from frozen dark, undaunted slim tulips blossom

\section{ปี \\ neuro-tangled brain, and yet \\ memories blossom}

Constructing these poems from words drawn at random from a little cloth bag is, I have found, a self-revealing process. Although the form is strict - a 5-syllable line, a 7-syllable line and another 5-syllable line - it provides enough scope to reflect on my particular stage of life, my love of nature, and healing themes.

gentle spiral down

called to dark, nourishing ground

a leaf carves her path

willow once weeping

windblown limp branches twisting

now hand-woven chair

midlife wants a cat

with two a.m. sweats and frets

perfect companion

lichen clings brittle

with crevice-rooted cedar

rock solid marriage

Some days in the emergency department inspire more unusual poetry, which I think of as "psycho haiku":

out of frying pan

flips manic energy swing

into dancing fire

code white certify

in secure facility

like catch and release

paranoia spins

relentlessly drives mind fields

eccentricity

downward social drift

day by day spare change sustains

no place in this world

\section{Elspeth MacEwan}

Lanark County Mental Health

(Crisis Team)

Ottawa, Ont.

\section{REFERENCE}

I. Dupont LH. The Haiku Box. Vermont: Journey Editions; 200I. 